\title{
Application of biological deodorization methods in the aspect of sustainable development
}

\author{
Urszula Miller ${ }^{1,}$, Izabela Sówka $^{1}$, Agnieszka Grzelka ${ }^{1}$, and Marcin Pawnuk ${ }^{1}$ \\ ${ }^{1}$ Wrocław University of Science and Technology, Faculty of Environmental Engineering, \\ 13 Grunwaldzki Square, 50-377 Wrocław, Poland
}

\begin{abstract}
The sequence of actions in matters of restricting odour nuisance is topped by preventive actions taken while an investment is planned and exploited. However, if using the best techniques available and abiding by technological regimes is insufficient and emission is still observed, one should make use of the method of deodorization. The choice of the specific suitable method is determined by many factors such as the properties of the gases being cleaned, the concentration of the pollution being emitted and the designed cleaning efficiency. Odour emission management concerning sustainable development should, therefore, comprise the required level of gas cleaning, the economic balance sheet of the investment and the acquired environmental effects. In the instance of biological methods, especially gas biofiltration, the cleaning process is carried out without virtually any side products, which would produce waste. Biofiltration is more and more commonly used in cleaning waste gases, because of both ecological reasons and economical competitivity with other methods. The balance of costs of an investment in biological gas deodorization along with its profits, as well as the ecological benefits coming from the usage of such methods, are presented in this work. The obtained cleaning efficiencies have also been included.
\end{abstract}

\section{Introduction}

Gases containing volatile organic compounds can be purified by physical, chemical or biological methods. The selection of the appropriate technique is determined by factors such as: gas properties, concentration of emitted pollutants, type of emission source, designed purifying efficiency. The variety of these parameters makes it difficult to find one universal method of purification. The condition of using biological methods of gas cleaning is the susceptibility of pollutants to biodegradation. The purification mechanism is based on two main processes: sorption and biodegradation. Biofilters are the most popular biological methods. The biofilter's operation consists in a slow flow of gas through a moist porous stationary bed. Pollutants are absorbed in water, which the bed is humidified, and thus to the biofilm, where they are biodegradable. In addition to biofilters, the methods of biological gas cleaning include: bioscrubbers, biotrickling filters and biomembranes [1]. Other types of biological reactors are used much less frequently. They are more technologically complex,

${ }^{*}$ Corresponding author: urszula.miller@pwr.edu.pl 
their exploitation is more difficult, and costs higher at every stage, from investment to use, compared to traditional biofilters [2].

\section{Ecological aspects}

Biofiltration, as a method of cleaning waste gases, is practically waste-free process. This is possible due to the purification mechanisms used in the biofiltration process, namely biodegradation that use aerobic microorganisms. As a result of absorption and biodegradation, pollutants contained in cleaning gases are decomposed mainly into carbon dioxide, water and biomass with heat emission [3]. Biodegradation processes occur in the inside of filter bed. We can distinguish both organic and inorganic materials used for the construction of filter beds [4]. In the case of biofilters made of organic matter we distinguish materials such as peat, soil, wood chips and other wood waste (including coconut fibers) and compost [1]. These materials can be easily obtained. Their source may be the conscious cultivation of plants, animal husbandry or can be obtained as a result of the management of plant, animal or municipal waste, an example of such material is compost, which is produced as a result of aerobic treatment of waste. These can be either animal or vegetable waste, municipal solid waste or even sewage sludge. Due to its nature, compost is very useful because, in itself, it contains a large number of microorganisms, which can be effectively used in the gas cleaning process [5].

Materials used in biofiltration are characterized by specific properties such as: adequate moisture and water retention capacity, porosity, $\mathrm{pH}$, specific surface area and mechanical strength [6], which guarantee the effectiveness of biofiltration. An important factor resulting from aforementioned properties is the time of usefulness of the bed filter material in the biofiltration process. The deterioration of the properties of filter bed is connected with the necessity of their replacement. The organic nature of these filter bedding materials is also a factor that affects their lifespan. As well as pollutants contained in the gas being cleaned, the filter material itself is susceptible to biological degradation processes. In general, organic filter bedding materials are considered to be those that require much more frequent exchange than in the case of inorganic materials. The lifetime of organic materials such as compost, is approximately 2 years and in the case of inorganic materials the time is about from 10 to 15 years [7].

As mentioned at the beginning, biofiltration is almost a waste-free process. The first stage of biofiltration [8] is the adsorption of odorous contaminants on the surface of the biofilm produced on the filter bed. Pollutants go into the liquid phase and diffuse towards the microorganisms. Then the process of proper biodegradation takes place, it takes place in two stages. The first stage is a biosorption, involving the retention of odorous contaminants on the surface of the cells, where the exchange of ingredients into the inside and enzymes outside the cells take place. This allows continuous surface regeneration and further biodegradation processes The next step is the mineralization of organic compounds using enzymes. These processes require oxygen conditions [8]. The biofiltration mechanism using microorganisms leads to the growth of new biomass, which allows the self-regeneration of the filter bed material [8] and cause the reduction of waste. Only two main by-products of this process can be distinguished. They are successively leachates and used filter beds. The waste filter beds, due to their organic nature, can be successfully used as, for example, a fertilizer used in gardening [9]. They can also be used successfully as a material in composting or fermentation processes that can lead to the production of useful products such as compost or methane, which can be used as an energy source. Such processing of organic material, according to Polish law, can be treated as a type of organic recycling. Re-composting of used bed filters with for example other waste can cause that it will be recovered again in the biofiltration process, because, as a mentioned before, compost can be used for making bed filters. 
Biological treatment of biodegradable waste including used bed filter materials generates many environmental benefits, for example [10]:

- reduction of waste generated (organic recycling),

- stabilization in terms of hygiene and sanitary conditions,

- reduction of the amount of waste sent to landfills, which results in longer exploitation time.

The leachates may only appear in the case of excess water in the filter bed. An excessive amount of water can be caused by too much humidity of the gas being introduced to the biofilter or it can appear as a result of excessive rainfall in the case of open filters [11]. Leachates from biofilters usually have a high biochemical oxygen demand and high concentrations of nitrate as a result of biological decomposition [12]. In some cases, due to the formation of acid degradation products, drainage can be characterized by a low $\mathrm{pH}$ [13]. In the majority of cases, they can be easily managed just by recirculation to the filter bed. They can be used to properly maintain humidity. However, too much humidity can cause an anaerobic conditions in the filter bed, which will reduce the effectiveness of biofiltration and can cause odour emissions.

\section{Economic analysis}

Biofiltration, in comparison with other deodorization methods, is characterized by one of the lowest operating and investment costs $[14,15]$. However, it should be remembered that there is a significant investment in the construction of the system. Another big expense is the necessity of periodic replacement of the packing material (depending on the type of packing material, every $2-5$ years). Fig. 1 . shows the average total investment costs as well as annualized investment and operating costs estimated for the biofilter installation with parameters: $\mathrm{Q}=20000 \mathrm{~m}^{3} / \mathrm{h}, \mathrm{V}_{\mathrm{h}}=400 \mathrm{~m}^{3}$, EBRT $=60 \mathrm{~s}$ (empty bed residence time), for a service life of 15 years [16]. The investment costs of such an installation have been estimated at 56,000 $€$, the annualized operating costs constitute the largest expenditure and amount to $25,750 €$, while the investment costs and the costs of packing material replacement are $6,600 €$ and $9,820 €$, respectively.

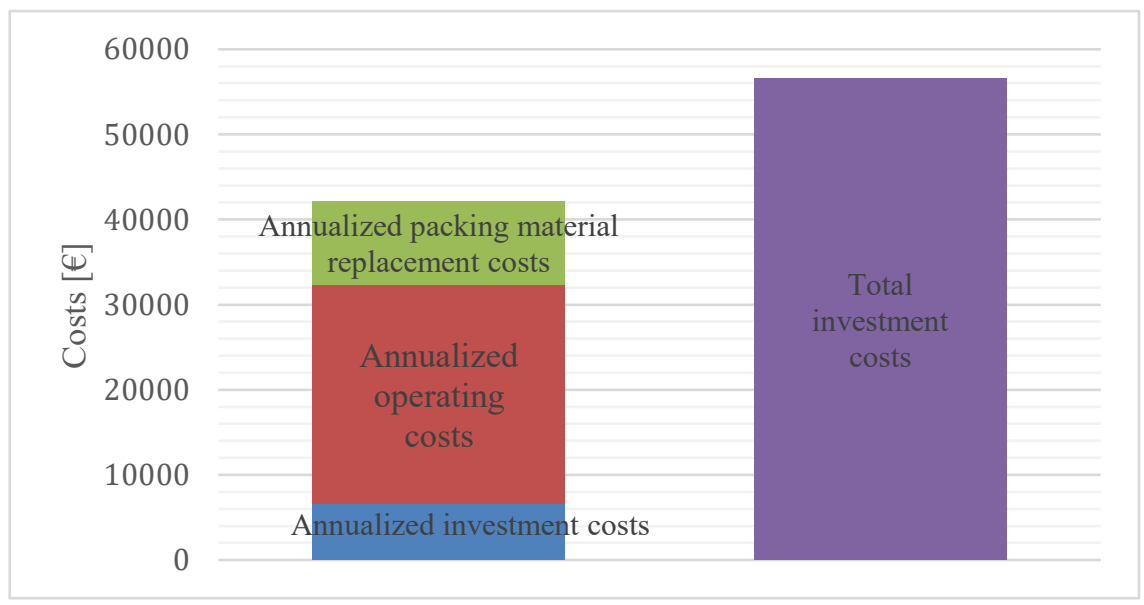

Fig. 1. Investment, operating and medium replacement costs estimated for an average-sized conventional biofilter [16].

In the biofiltration method, the investment costs are influenced the most by the installation parameters such as empty bed residence time and the cost of the packing material. An 
important factor that may result in additional capital costs is when the land available is limited or there is a relatively high price of the land. It should also be borne in mind that besides the scale and the proposed efficiencies of odor-abatement systems, the final investment costs may be influenced by such factors as [17]:

- installation costs (about $25 \%$ of the cost),

- instrumentation,

- ductwork,

- project management,

- manufacturing location,

- sales commission and other.

Fig. 2. shows the Comparison of investment costs of biofiltration with other deodorization methods such as biotrickling filtration, activated carbon filtration and chemical sorption presented per unit of flow rate treated. It can be noticed that with the increase of the projected flow rate of the installation, the unit costs significantly decrease. In the case of biofiltration investment cost are from $5 €$ per $1 \mathrm{~m}^{3} / \mathrm{h}$ (for the flow rate of $100000 \mathrm{~m}^{3} / \mathrm{h}$ ) to $28 €$ per $1 \mathrm{~m}^{3} / \mathrm{h}$ (for the flow rate of $20000 \mathrm{~m}^{3} / \mathrm{h}$ ). In the case of the design of installations for high flow rates (e.g. $100000 \mathrm{~m}^{3} / \mathrm{h}$ ) of gases, the investment costs of biofiltration are comparable with respect to other methods of deodorization, such as activated carbon filtration and chemical sorption and definitely lower than in the case of biotrickling filtration.

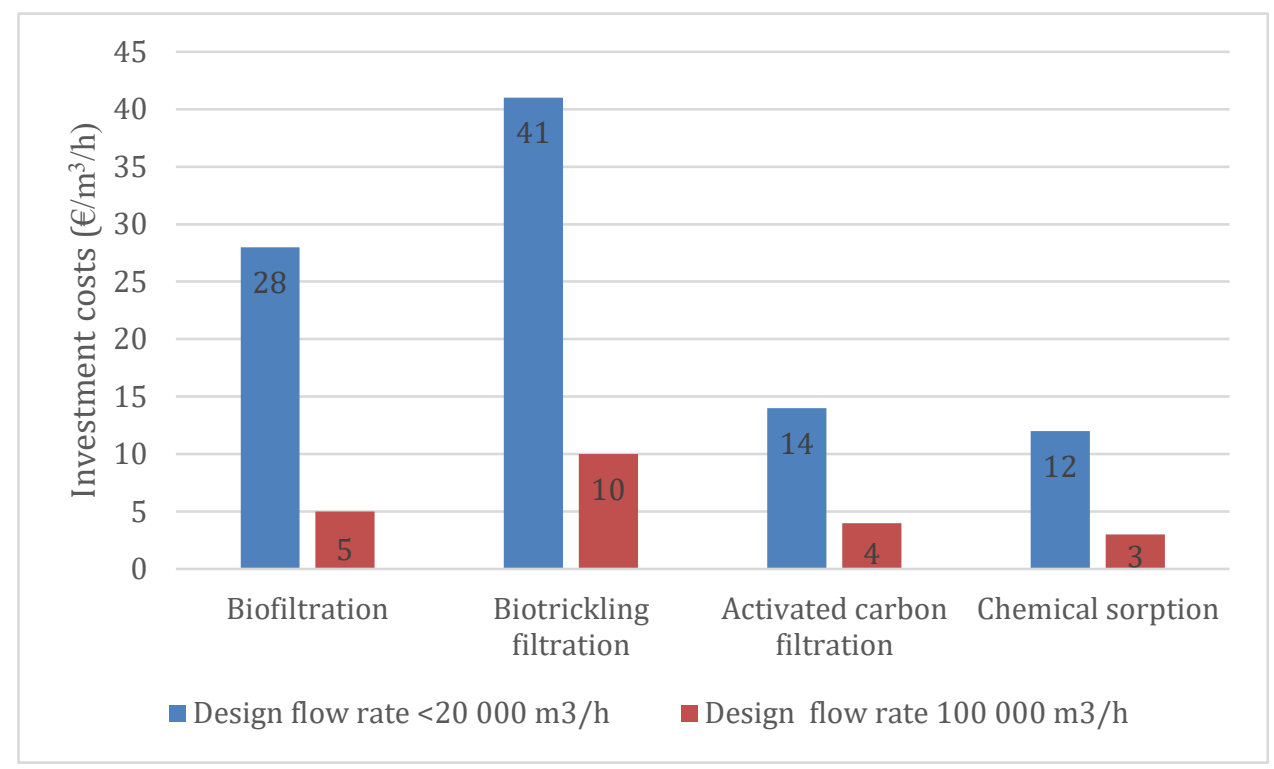

Fig. 2. Comparison of investment costs of biofiltration with other deodorization methods [17].

With regard to operating costs, the largest expenditure in the case of biofiltration generates the need to periodically exchange packing material, therefore the amount of these costs is indirectly influenced by the type of packing material used (market prices of materials are very different, as well as their durability). Other factors that determine the amount of operating costs are energy and water consumption. The "work" expenses consist of labor, transport and handling, disposal and maintenance also related to the necessity of packing media replacement. Table 1 . shows comparison of operating costs of biofiltration with other deodorization methods (biotrickling filtration, hybrid system (biotrickling filtration + activated carbon filtration), chemical scrubbing and activated carbon filtration) [18]. The unit operating costs of biofiltration are lower than the costs of other methods except 
biotrickling filtration. Taking into account both investment and operational costs, biofiltration turns out to be the most economical of available deodorization methods.

Table 1. Comparison of operating costs of biofiltration with other deodorization methods [18].

\begin{tabular}{|c|c|c|c|c|c|c|}
\hline \multirow[t]{2}{*}{ Method } & $\begin{array}{l}\text { Operating } \\
\text { costs }\end{array}$ & Water & Energy & $\begin{array}{l}\text { Packing material } \\
\text { replacement }\end{array}$ & Work & Chemicals \\
\hline & $\epsilon$ per $\mathrm{m}^{3} / \mathrm{h}$ & \multicolumn{5}{|c|}{ Annual cost in $€$ estimated for a flowrate of $50000 \mathrm{~m}^{3} / \mathrm{h}$} \\
\hline Biofiltration & 2.0 & 6000 & 18000 & 47000 & 29000 & - \\
\hline Biotrickling filtration & 1.2 & 12600 & 13200 & 26400 & 7800 & - \\
\hline $\begin{array}{l}\text { Hybrid (biotrickling } \\
\text { filtration }+ \text { activated } \\
\text { carbon filtration) }\end{array}$ & 2.7 & 12150 & 43200 & 55350 & 22950 & - \\
\hline Chemical scrubbing & 3.6 & 5400 & 39600 & 7200 & 5400 & 124200 \\
\hline $\begin{array}{l}\text { Activated carbon } \\
\text { filtration }\end{array}$ & 7.2 & - & 32400 & 237600 & 90000 & - \\
\hline
\end{tabular}

\section{SWOT analysis}

The SWOT analysis determines strengths, weaknesses, opportunities and threats. The analysis allows to assess material and non-material factors affecting the success of the investment. The analysis was carried out for biofiltration installation intended for gas deodorization (Table 2.).

Table 2. SWOT analysis for biofiltration installation as a method of gas deodorization.

\begin{tabular}{|c|c|c|}
\hline \multirow[b]{2}{*}{ : } & $\begin{array}{c}\text { strengths } \\
\end{array}$ & weaknesses \\
\hline & $\begin{array}{l}\text {-the possibility of underground } \\
\text { infrastructure plan } \\
\text { - no waste } \\
\text { - no sewage - possibility of recirculation } \\
\text { - high treatment efficiency } \\
\text { - the possibility of composting used } \\
\text { filter material } \\
\text { - relatively low investment and } \\
\text { operating costs }\end{array}$ & $\begin{array}{l}\text { - large area of biofilter } \\
\text { - high sensitivity of the method to } \\
\text { external factors } \\
\text { - the need to control gas and bed } \\
\text { parameters (humidity, } \mathrm{pH} \text { ) } \\
\text { - the need to provide qualified service }\end{array}$ \\
\hline \multirow[b]{2}{*}{ 矛 } & opportunities & threats \\
\hline & $\begin{array}{l}\text { - the possibility of obtaining funds for } \\
\text { supporting pro-ecological activities } \\
\text { - the availability of filter material }\end{array}$ & $\begin{array}{l}\text { - complaints about odor nuisance in case } \\
\text { of failure } / \text { reduction of cleaning } \\
\text { efficiency }\end{array}$ \\
\hline
\end{tabular}

While maintaining optimal biofilter conditions, defined treats should not occur, and the risk is compensated by the effectiveness of deodorization and economic factors. Biofiltration is used in various areas: in waste management and water and sewage management facilities, as well as in many branches of industry, including in the chemical industry. Both odors and other impurities in the treated gases are removed, such as: aliphatic, aromatic, oxygen, sulfur, nitrogen and chlorine compounds. In the case of hydrogen sulphide removal, the efficiency achieved is usually at least $99 \%$, with a wide range of inlet concentrations of pollutants, however, due to the risk of acidification of the bed, they pay attention to the need to regulate its $\mathrm{pH}$. In the case of ammonia, lower efficiencies are obtained than for hydrogen sulphide (up to $98 \%$ ), which may result from the slow growth of nitrifying bacteria capable of ammonia oxidation, and recirculation into the leachate deposit containing ammonium radicals easily decomposed to ammonia and hydrogen $[6,19]$. The effectiveness of removing 
volatile organic compounds depends on a large extent on their solubility in water and vapor pressure values, which makes the range of effectiveness achieved is high, and the deodorization efficiency is conditioned by the composition of the gas being purified [6].

\section{Summary}

Biofiltration as a method of gas deodorization perfectly fits into the assumptions of the idea of sustainable development. While maintaining economic viability, it allows effective gas cleaning, thus preventing odor nuisance. In addition, biofiltration has an ecological advantage over other methods of gas purification - it is based on the natural degradation processes occurring in the environment and is practically waste-free. Despite the sensitivity of the method to external factors, the behavior of technological regimes and optimal working conditions allows for an efficient and stable operation of the installation.

This work was supported by a statutory research No. 0402/0134/17.

\section{References}

1. S. Mudliar, B. Giri, K. Padoley, D. Satpute, R. Dixit, P. Bhatt, R. Pandey, A. Juwarkar, A. Vaidya, J Environ Manage 91 (2010)

2. R. Cudmore, P. Gostomski [in:] Biotechnology for Odor and AirPollution Control (Springer-Verlag Berlin, Heidelberg, 2005)

3. A.H. Wani, R. Branion, A.K. Lau, J EnvironSci Heal (1997)

4. Y. Cohen, Biofiltration - the treatment of fluids by microorganismimmbolizedinto the filterbeddingmaterial: a review (Department of Soil Sciences, Swedish University of Agricultural Science, Sweden, 2000)

5. K. Barbusinski, K. Kalemba, D. Kasperczyk, K. Urbaniec, V. Kozik, J Clean Prod 152 (2017)

6. D. McNevin, J. Barford, Biochem Eng J (2000)

7. A.D. Dorado, F.J. Lafuente, D. Gabriel, X. Gamis, Environ Technol 31, 2 (2010)

8. M. Wierzbińska, W. E. Modzelewski, Inż Ekolog 41 (2015)

9. A. Kwarciak-Kozłowska, B. Bańka, Inż Ochr Śr 17, 4 (2014)

10. P. Manczarski, Kompostowanie odpadów komunalnych, POLEKO, Poznań (2007)

11. C. Easter, C. Quigley, P. Burrowes, J. Witherspoon, D. Apger, Chem Eng J 113 (2005)

12. R. Nicolai, D. Schmidt, Biofilters (LivestockDevelopment in South Dakota: Environment and Health, 2005)

13. G. Leson, A.M. Winer, J Air Waste Manag 41, 8 (1991)

14. M. Langolf, G.T. Kleinheinz, Bioresource Technol 97, 15 (2006)

15. J.S. Devinny, M.A. Deshusses, T.S. Webster, Biofiltration for Air Pollution Control, (CRC Press, Boca Raton, FL, 1999)

16. O.J. Prado, D. Gabriel, J. Lafuente, J Environ Manage 90 (2009)

17. J.M. Estrada, N.J.R. Bart Kraakman, R. Munoz, R. Lebrero, Environ Sci Technol 45 (2011)

18. J.M. Estrada, N.J.R. Bart Kraakman, R. Lebrero, R. Munoz, Biotechnol Adv 30 (2012)

19. J.E. Burgess, S.A. Parson, R.M. Stuetz, Biotechnol Adv 19 (2001) 